\title{
EXPERIMENTATION THROUGHOUT THE PRODUCT DEVELOPMENT PROCESS - LESSONS FROM FOOD AND BEVERAGE VENTURES
}

\author{
Kukko-Liedes, Ville; Mikkonen, Maria; Björklund, Tua \\ Aalto University
}

\begin{abstract}
Established companies turn to new ventures for bolstering exploration activities, but we know relatively little of the product development processes of startups and new ventures and how different stakeholders are utilized in these. The current study investigated the product development activities and experiments of eight Finnish food and beverage ventures in a multiple case study based on 22 interviews. How the developed products fit into the existing portfolio and experience of the ventures seemed to define their enacted development process. Internal experimentation was a constant feature, although the type of experiments varied between different phases of the development process. External-facing experiments were less frequent and more for validation than concept generation. On the other hand, they also carried important market creation functionalities. The results suggest that more nuanced terminology around experimentation would be useful to determine what type of experiments serve different goals in the development process.
\end{abstract}

Keywords: Organisation of product development, Innovation, Process modelling, Experimentation, New ventures

Contact:

Kukko-Liedes, Ville

Aalto University

School of Engineering

Finland

ville.kukko-liedes@aalto.fi

Cite this article: Kukko-Liedes, V., Mikkonen, M., Björklund, T. (2019) 'Experimentation Throughout the Product Development Process - Lessons from Food and Beverage Ventures', in Proceedings of the 22nd International Conference on Engineering Design (ICED19), Delft, The Netherlands, 5-8 August 2019. DOI:10.1017/dsi.2019.120 


\section{INTRODUCTION}

The importance of entrepreneurship and entrepreneurial behavior is widely recognized to contribute towards the renewal of industries and individual organizations (Acs et al., 2013; Audretsch, 2002; Audretsch et al., 2008; Shepherd et al., 2015). Faced with limited resources, entrepreneurs need to creatively make do with what they have (Baker and Nelson, 2005; Fisher, 2012). However, while large organizations may recognize the need to balance exploitation with exploration (March 1991; Uotila et al., 2009; Phene et al., 2012), the iterativeness and sustained ambiguity of multiple rounds of experimentation can be hard to adopt (Rekonen and Hassi, 2018).

The food industry is an intriguing area for studying product development as it is an extremely competitive field and has seen a shift in operations from supply-based to demand-based due to the saturated markets in developed countries created by the advancements in agriculture and food processing technology (Linnemann et al., 2006). Consumer-orientation has long been promoted as one of the key success factors in food product development (Earle et al., 2001) and continues to be emphasized for mitigating product development risks and failure (Grunert and van Trijp 2014). Despite these efforts, the rate of failed new consumer food products has remained at a high level for more than thirty years (Suwannaporn and Speece 2010).

Product development process theory is built on the foundation of structured processes - almost exclusively grounded to Cooper's (1983) stage-gate model and its derivatives- and the food industry is no exception (Earle et al., 2001). Formal processes are a norm in the field of product development, with a study sponsored by Product Development and Management Association showing 69 per cent of its member corporations using formalized product development processes (Barczak et al., 2009). Meanwhile, idea generation and management linked to the front-end phase of PD process is still lacking in many corporations (ibid), even though experimentation and prototyping are central parts of the product development process (Ulrich \& Eppinger, 2012; Ries, 2011). It has also been recognized that companies need to adapt formal processes according to their contextual needs, which has led to more flexible process models such as the third-generation new product development process described by Cooper (1994).

Research on the product development processes of smaller ventures is scarce (Hörte et al., 2008), but it is safe to assume formal processes are less common in these companies which have yet to establish long-rooted practices. Meanwhile, start-up companies are proclaimed for bringing forward innovations, and established firms are suggested to learn from their methods in this regard. Notably in the Finnish food industry, it has often been small ventures that have pioneered new product categories with their capability to experiment with new ideas in a more dynamic manner, while larger corporations follow in their efforts. This presents an incentive to study the product development efforts of smaller companies, which have been left largely neglected in product development research. Though many of these companies might not have formalized processes, all development behavior enacts a process of some sort. Studying the enacted processes through which new ventures develop their products can offer interesting insights into how their agile operations are enabled and organized. In particular, the current study aims to explore how new ventures in the food industry structure, time, and divide their development activities through a multiple case study of the enacted product development processes and experimentation activities of eight Finnish food and beverage industry ventures.

\section{METHODS}

In order to investigate the product development processes of food and beverage ventures, and more specifically, what, when, and with whom does experimentation take place with within these processes, we adopted a qualitative multiple case study design exploring both within-case variation and betweencase differences (Eisenhardt and Graebner, 2007). Data was collected through 22 semi-structured thematic interviews from 18 individuals working in eight food and beverage ventures in Finland (see Table 1). The interviews were conducted mostly face-to-face or via voice- or video-call when necessary. In most cases all original founders were interviewed. However, in a few cases not all founders could be reached, and in some cases non-founders were working in key development roles and they were also interviewed. The interviews typically lasted for an hour, and they were all audio- 
recorded and transcribed verbatim. Quotes have been translated into English for the purpose of presentation.

First, within-case analysis was initiated by forming detailed case trajectories of the development activities in the eight ventures based on all interviews. These trajectories enabled us to form an overall understanding of the key dynamics and venture events of all cases. The initial case selection was based on representing a variety of offering types; premium food, premium beverages and new types of food, and a variety of new food product categories following definitions gathered by Linnemann et al. (2006). However, examining the development actions and attitudes, it soon came apparent that these did not result in similar development processes. Rather, commonalities between ventures' development activities could be seen in their specific development goals and their correspondence to previous products. Three such process types, or development goals, were identified: developing new flavors within product categories, developing new-to-company product types, or revising previous product concepts (see Table 1). In addition to the primary mode of development, many cases also included product development activities that were secondary or less common than their primary way of developing. The case trajectories were constructed by identifying development activities and placing them in one of for development phases, ideation, concept development, product development, and delivery. These four phases were constructed based on product development process models by Cooper (1988), Ulrich and Eppinger (2012), and Earle et al. (2001) and adapting them to suit the development activities identified in the cases.

In the second round of analysis, we identified all instances of experimentation described in the interviews, noting at which stage of the product development process they were conducted. For this purpose, the success or outcome of these experiments was not assessed, although, the interviewees were asked to give one example of an experiment or a development effort that was deemed successful and likewise another unsuccessful, following the critical-incident approach (Chell, 2004; Flanagan 1954). This approach can help to reduce retrospective bias through focusing on participant-selected meaningful events of which subjects tend recall well (Chell, 2004). During analysis, activities were considered experimental borrowing definitions from academic literature of both engineering design (e.g. Ulrich \& Eppinger, 2012) and design thinking (e.g. Liedtka, 2014; Carlgren, 2016). Identified experiments were categorized based on thematic similarity (Braun and Clarke, 2006) into 15 different types of experiments, and grouped together based on being conducted either internal experiments, or experiments conducted with or facing external stakeholders such as distributors or consumers (Figure 1).

Table 1. The eight food and beverage venture cases

\begin{tabular}{|c|c|c|c|c|}
\hline $\begin{array}{l}\text { Type of } \\
\text { offering }\end{array}$ & Venture & $\begin{array}{l}\text { Food } \\
\text { product } \\
\text { category }\end{array}$ & $\begin{array}{l}\text { Most frequent relation of } \\
\text { developed products to } \\
\text { existing offering }\end{array}$ & $\begin{array}{l}\text { Conducted } \\
\text { interviews }\end{array}$ \\
\hline \multirow[t]{3}{*}{$\begin{array}{l}\text { Premium } \\
\text { Food }\end{array}$} & IcecreamCo & $\begin{array}{l}\text { Line } \\
\text { Extension }\end{array}$ & $\begin{array}{l}\text { Primarily flavor variants, } \\
\text { secondarily new-to-company }\end{array}$ & Three founders \\
\hline & ChocolateCo & $\begin{array}{l}\text { Me-too, } \\
\text { Innovative } \\
\text { product }\end{array}$ & $\begin{array}{l}\text { Primarily new-to-company, } \\
\text { secondarily flavor variants } \\
\text { and revisions }\end{array}$ & $\begin{array}{l}\text { One founder and one } \\
\text { key employee }\end{array}$ \\
\hline & HoneyCo & Me-too & $\begin{array}{l}\text { Primarily new-to-company, } \\
\text { secondarily flavor variants }\end{array}$ & Two founders \\
\hline \multirow[t]{3}{*}{$\begin{array}{l}\text { Premium } \\
\text { Beverage }\end{array}$} & TeaCo & $\begin{array}{l}\text { Line } \\
\text { Extension }\end{array}$ & Primarily flavor variants & Two founders \\
\hline & SpiritsCo & Me-too & Primarily new-to-company & $\begin{array}{l}\text { One founder and one } \\
\text { key employee }\end{array}$ \\
\hline & CoffeeCo & $\begin{array}{l}\text { Line } \\
\text { Extension, } \\
\text { New Form }\end{array}$ & $\begin{array}{l}\text { Primarily flavor variants, } \\
\text { secondarily new-to-company }\end{array}$ & $\begin{array}{l}\text { One founder and one } \\
\text { key employee }\end{array}$ \\
\hline \multirow[t]{2}{*}{ New Food } & ProteinCo & $\begin{array}{l}\text { Creative } \\
\text { Product }\end{array}$ & $\begin{array}{l}\text { Primarily revision, } \\
\text { secondarily new-to-company }\end{array}$ & $\begin{array}{l}\text { Three founders and } \\
\text { one key employee }\end{array}$ \\
\hline & GrainCo & $\begin{array}{l}\text { Creative } \\
\text { Product }\end{array}$ & Revision, new-to-company & One founder \\
\hline
\end{tabular}




\section{RESULTS}

\subsection{The context of the experiments: The three types of patterns in product development processes}

Three types of development goals in relation to the existing offering of the ventures were used to categorize the development processes of the cases:

1. flavor variant development, extending existing lines of products of the venture with new flavors

2. new-to-company development, creating products of which the entrepreneurs had no previous experience in, and

3. revision development, relaunching products which had been iteratively modified.

The first group of ventures currently focusing on flavor variants included three cases: IcecreamCo, TeaCo, and CoffeeCo. All three companies had experience in multiple similar products, which had resulted in a rather established development process. These companies released the most products out of all of the cases in the study and launched them at the highest frequency. CoffeeCo gave a typical product development phase length of two months from ordering ingredient samples to introducing the product to the market. Similarly, IcecreamCo aimed to launch three to five new flavors a year. The length of the whole process in TeaCo, on the other hand, could range from as short as one month to more than a year, as the company emphasized market validation through business-to-business customers with a finished product before making it available for retail. In these three ventures, the ideation phase focused on constantly being on the lookout for flavor ideas from multiple sources, often inspired by ingredients, seasons or collaboration. The concept development and product development phases merged together, the transition being fuzzy from one to the other. Multiple ideas were tested and refined at a concept stage, moving then quickly to detailed design of recipes and packages. Once the product neared ready for market, the three cases different in how they handled the delivery phase, for example depending on whether they had fixed release dates set by retailers or not.

Three further cases adhered primarily to new-to-company development activities: ChocolateCo, SpiritsCo, and HoneyCo. Most of their product development projects involved creating a product that the companies had no comprehensive existing experience in, regardless of whether similar products existed on the market or not. Unlike the three companies developing mainly flavor variants to existing products, these three case companies sought to build a wider product portfolio spanning beyond variations of a specific food or beverage product. Nonetheless, they all revolved around a core category or theme: ChocolateCo developed products based on chocolate, SpiritsCo alcoholic beverages, and HoneyCo food and wellness products utilizing honey or beeswax. Typical for these new-to-company development cases were longer development times and emphasizing concept validation. Ideation phases centered around their core ingredients or categories and was quite deliberate, although collaborating with other stakeholders could introduce less planned additions. In the concept development phase, however, ideas were then carefully tested and different alternatives weighed. The more detailed product development phase started in parallel to the concept development to some extent in all three cases, with manufacturability of these new-to-company products being an important consideration and topic of development. Nearing delivery, all three companies emphasized face-to-face meetings as an important way to sell their products, gathering feedback and making adjustments as needed, sometimes even after the product launch.

Finally, two case companies focused on revising created products: WheatCo and ProteinCo, both in the new food market. Both of these case companies were pioneering the use of an alternative core ingredient in Finland and produced foods in the creative product category. As such, they had had to go through extensive development efforts in the past to introduce their products to the market. This development had been closer to the new-to-company process, with the additional challenges of educating customers about the new kinds of products. However, both companies were at the time of the interviews working on products based on their existing or past offering, effectively creating revisions around a previous core concept, rather than creating more variety around a single product type as in the new flavor focused company cases. ProteinCo had two different types of food products, both of which had seen multiple iterations on the market and were going through another revision. WheatCo had introduced a newly positioned version of a product the company had carried some years back and had other products also which had seen multiple versions on the market. This long spanning iteration of product adjustment defined the revision type development process. Ideation phases focused on revisiting the longer histories of the products and lessons learned from these previous 
iterations. Depending on the type of revision, the concept development phase might not be visited, and the length of the detailed product development phase varied. Production was started only after the companies had gotten their products accepted to retailers. WheatCo made the first batches of the revisions small, as retailers wanted to verify the product sells before adding it to the permanent selection. ProteinCo interacted with customers in effort to promote their products and the new source of protein in general, but also viewed it as important to be the first-to-market and could launch revised products to stores very quickly.

\subsection{Experimentation at different phases of the product development process}

Experimentation as part of the product development process differed from one phase to another, and reflected the other activities happening at each phase. In the ideation phase, ideas were tested and developed further in internal prototyping or validated with external parties. In concept development, experimentation was primarily used to narrow down competing solutions and to clarify the concept, whereas in product development it guided detailed design, such as final flavor and recipe. Experimentation in the delivery phase included using of test batches to validate the market, and in some cases the final product itself was considered an experiment to test the reception of an idea. However, the companies did not follow clear patterns according to either the type of product they were developing or its positioning to the current offering. Rather, experiments differed from case to case. Experimentation themes are visualized around corresponding process phases in Figure 1, but it is to be noted that although the four phases are shown as distinctive steps that in theory could be present sequentially, their activities overlap and the actual process cannot be described as a sequential flow.

In general, most experiments were conducted internally, meaning no parties outside of the company were involved, and the focus was on developing the product to a more detailed level. This includes, for example, testing and improving the recipe or manufacturing process. More exploratory experiments that might have resulted in new or unexpected product or flavor ideas were positioned in the early phases of development process and were also conducted mostly internally. Reaching out to external parties, such as users or experts of the field, was done in all phases, but these were rare events when compared to the continuous internal testing going on at all ventures. Moreover, feedback from outside the company was used primarily as validation for the existing development direction, rather than as a guide for future development.

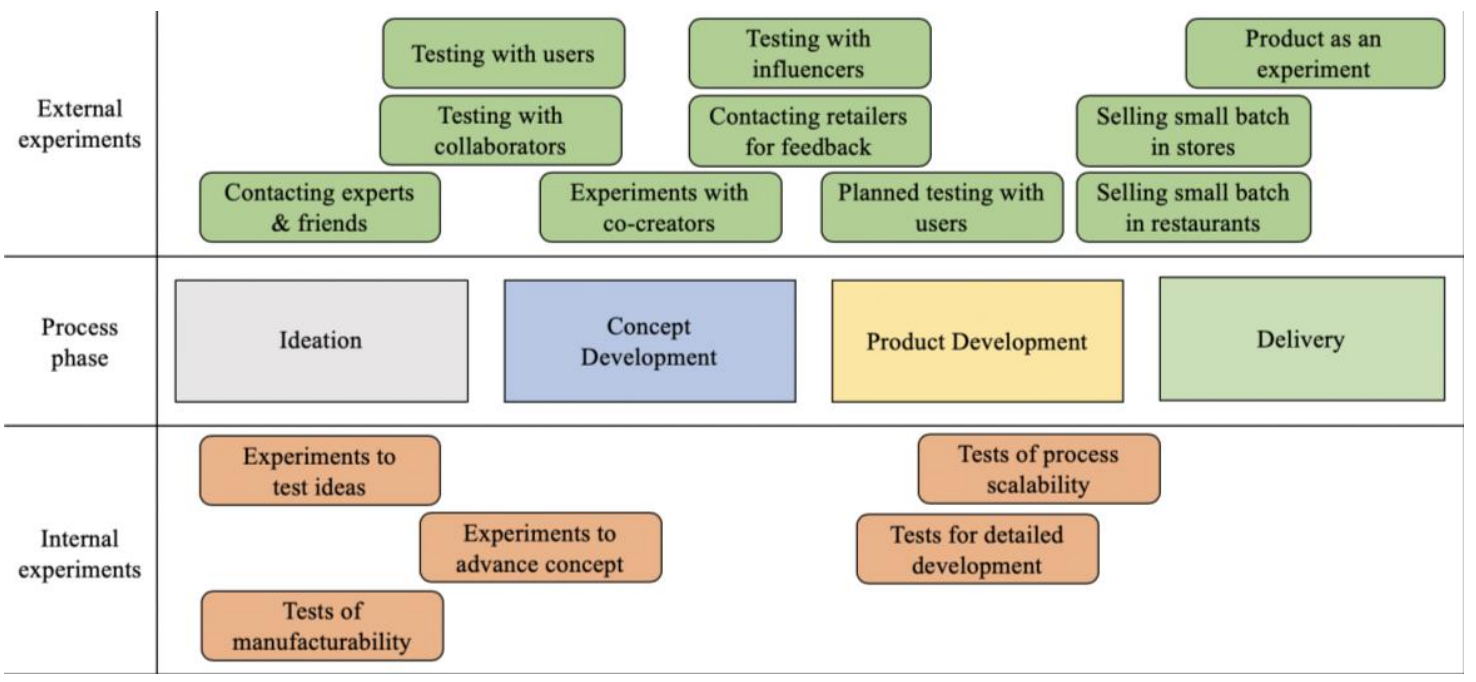

Figure 1. Internal and external-facing experiments at different product development phases

\subsubsection{Experiments in the ideation phase}

Including external parties to experimentation in ideation phase of product development process was limited to founders reaching out to their friends or to experts in the field in order to gather feedback or validate product ideas. Otherwise experimentation in this phase related to testing if an idea works in its simplest form and was conducted largely internally. For example, in the case of IcecreamCo, this meant conducting initial tests on gathered flavor ideas. These experiments were a planned part of the process as IcecreamCo started with multiple potential ideas, which were narrowed down in the later concept development phase. In contrast, all companies in the new-to-company group conducted first 
experiments impromptu as an idea or an opportunity for a new product emerged. The founder of HoneyCo founder gave an example of a successful experiment of trying a new product idea that gave them confidence to potentially proceed to launching it:

"And now [one founder] actually just conducted an [experiment on a new beeswax product]. It went really well. These products keep coming now, the [wax product] is possibly our next one, our third product. It went well and was surprisingly easy to do. Overall there are not too many elements, but even then things can go wrong. So the experiment went well, we actually succeeded on our first try." (HoneyCo)

\subsubsection{Experiments in the concept development phase}

Internally facing experimentation was used in concept development phase to advance product ideas further and to narrow the number of ideas. The formality of these experiments as part of the process differed between cases. For example, SpiritsCo planned for testing that would have to be finished on a concept before assessing whether to continue or stop the development on that product, and IcecreamCo as part of their process conducted iterative testing and development on multiple concepts until at least one was promising to move to detailed development. On the other hand, companies such as CoffeeCo, TeaCo and ChocolateCo, who did not have distinct concept development phases or had it run parallel to product development, would at the same time advance the detailed development of a product and build the concept around it without much experimentation guiding the concept creation or selection. For example, ChocolateCo included their production operations and in-house graphic designer from the start to proceed testing manufacturability and packaging. In the case of TeaCo, experimentation focused on recipe development that followed a strong guiding concept idea, whereas decisions on details such as name and packaging introduced in much later phases.

Experimentation with external parties during concept development was visible especially in the case of collaboration or commissioned products where the partner company would join the tastings and guide the concept and early product development. Users opinions were sought less frequently in concept development phase, although this did also happen indirectly. Especially ProteinCo of revision development group gained user feedback through events where they promoted the new source of protein foods and served their product, which was still under development. With much more direct approach, SpiritsCo conducted early experiments on one of their products through longer co-creation with experts. Similarly, GrainCo developed their just-add concept based on a day of development and testing done with an expert with users tasting the products.

"[It was] mostly just the two of us. And then there were also those customers from the bar, who tasted and gave feedback. From those comments Heikki, my chef friend, adjusted the ingredient proportions right. Not just right, but also that what is for example the reasonable amount of blueberries in a [grain] product." (GrainCo)

\subsubsection{Experiments in the product development phase}

Experimentation in product development phase guided the detailed design of the product. This included, for example, recipe refinement, texture, and manufacturability of the product itself as well as packaging size, labeling, and flavor options. Experimentation to guide decisions on these matters was conducted mainly internally, with multiple iterations focusing on the product itself, and less on the packaging side. However, GrainCo, which relied on its networks on most operations also used processing partners for recipe development. Similarly, ProteinCo, had made use of a day of outsourced $R \& D$ service for recipe refinement for one of their product revisions, although the product was based on extensive internal development.

The graphical design of the product, including the packaging and marketing material, saw little experimentation during the development process. ChocolateCo, HoneyCo and CoffeeCo had in-house designers, whereas other companies relied on external designers or agencies. Decisions on design were made internally, for example, in the case of CoffeeCo, going through proposals in company's internal messaging board with everyone given the possibility to voice their opinions. In ChocolateCo, which also had an in-house designer, the situation was similar, although other employees chose to mostly trust the designer's discretion. For many companies, the packaging design saw major changes only after longer periods. For example, ChocolateCo changed the visual look of all of their products as part of a brand refresh. SpiritsCo designed their own bottle for their key products to replace a white label 
solution. Although many companies emphasized the importance of packaging, TeaCo showed the most affection towards this topic as both of the founders mentioned packaging multiple times in their interviews. Their packaging had gone through many major changes over the visual as well as physical form as the founders refined it to better suit their wishes and customer needs.

"From the start, packaging was important to us, that is looks good and tells the same story as our teas. And as difficult shaped as is our current one, composed of two cylinders - one in the other. It was what we wanted and we couldn't find the right ones." (TeaCo)

"We're really proud that we've moved away from the first package. But we also have invested a bit in the new version. It's a shame that there are so many food companies here in Finland, who have a great tasting product, but the outlook doesn't match in any way the product itself" (TeaCo)

External parties were used the most in the experiments of the product development phase. This was done both to validate the product prior to launch and to guide the detailed design. ProteinCo and GrainCo used feedback from major retailers to adjust the products and wished to close sales contracts before investing in packing and production. IcecreamCo also sold their products through the same major retailers, but they did not rely on their feedback or validation. On the contrary, the founders would cancel the delivery of a pre-sold product to a retailer if they could not in their own opinion achieve the quality for the product they were looking for.

User testing in the product development phase was a part of IcecreamCo's process as they often sought external feedback by organizing comparative tastings and by sending out samples to volunteers. They used this information to guide their decisions on the recipe development, as opposed to for example ChocolateCo, which organized one tasting on their at the time latest product to validate the positive reaction from users they were hoping for. SpiritsCo showed most variety in the ways they carry out experimentation with external stakeholders. During the development of their first product, they set up a pop-up store in which they served variations of the product in order to collect feedback and to learn about customer preferences. They reached out to bartenders for similar feedback, although one of the founders indicated this was primarily done as a marketing effort. In case of two of their later products, the company had conducted a tasting with users. Both, one of the founders and a key person in the company, pointed out insights learned from these sessions that guided the recipe development to a direction they would not have reached with only internal testing.

"From the blind testing used for the first liquid, we noticed that there is a problem in the smell of the product. Even if the taste is good, that 'something's off' in the nose, which wouldn't have been noticed without the feedback from a 'normal' user. So in those types of things [experimentation] are really useful, "cause we can directly affect the outcome" (SpiritsCo)

Other experimentation efforts including external parties in product development phase included HoneyCo's multiple user testing sessions of their non-food product, conducted in the actual use context. The company had also used bloggers to review their non-food product. They had planned to release the product shortly, but negative feedback refrained them from doing this and got them to consider a more thorough approach to similar future products.

As the delivery of the finished products was approaching, the experiments tended to relate to setting up appropriate manufacturing processes. In some cases, such as ChocolateCo, manufacturing had been taken into account from early stages, whereas in case of IcecreamCo changing from smaller batch machinery used for prototyping to large production machines affected the product to an extent that recipe had to be adjusted. Simpler recipes, such as TeaCo's, remained unaffected from the change from development to production of finished products.

\subsubsection{Experiments in the delivery phase}

Experimentation in the delivery phase was rare as the companies usually had finished their products at this point. However, SpiritsCo and TeaCo were exceptions, as SpiritsCo included a six-month period after product launches to adjust the recipe based on feedback, and TeaCo validated their products with restaurant sales before finishing packaging design and moving a product to retail. Even after moving to retail, the company would start with a smaller test batch, which would only be scale up if the product sales were satisfactory. SpritisCo founder voiced the ease of gathering feedback on a food or beverage product from users in a face to face setting, but also the difficulty that relates to measuring 
the actual use behavior past the sales. GrainCo and ProteinCo, who approached delivery by validating the product with major retailers during development, also started sales with smaller test batches. However, they stated this practice came from the retailers who wanted to assess the demand by sales before committing to larger orders or wider distribution.

Some companies considered entire products as a form of an experiment and used their sales as a meter of success. This was the case especially with ChocolateCo, CoffeeCo, and ProteinCo. ChocolateCo and CoffeeCo approached product development by pushing products through to market. Key person from ChocolateCo explained that, although this approach had its downsides, it was done to avoid getting stuck with ideation and to get to test the product.

"Well, it was sort of an experiment, the product was in the stores. It was our style of doing [an experiment]. But somehow [my co-founder] said nicely, you'll hear about it more soon, that 'let's stop ideating, let's just do it'. It is a bit more challenging to always do the whole process to the end, to the stores, to be able to fully test it. However, we still want to do these tests at the store shelves." (ChocolateCo)

Continuously releasing products and iterating based on market reception had been typical of ProteinCo's development process. Treating a product as an experiment has been key to this approach. In case of ProteinCo, the founders stated the product category of a new source of protein was difficult, as customers could not voice their needs to a new food they had not encountered before.

\section{DISCUSSION}

The current study set out to investigate the enacted product development process and related experimentation activities of eight food and beverage ventures in Finland. While startups may not have a formalized development process, activity patterns - development processes in action - could be found in the cases depending on how the product development goal aligned with the existing offering of the company. Ventures focusing on flavor variants were constantly on the lookout for new ideas, had fuzzy transitions between the concept and detailed development, and tested multiple ideas. Companies focusing on creating products new to their portfolio emphasized more concept development and manufacturability, while those revising existing products might virtually skip concept or detailed development phases. Across cases, these enacted processes gained formality over time as the companies increased their experience and endured setbacks from development mistakes.

Increased formality in the case companies' processes was seen in two forms. First, formality showed as best practices that were acquired during a more explorative phase of initial product and opportunity development. This effect is related to imprinting: significant founding conditions imprint on ventures and have long lasting effects (Levinthal, 2003). Imprinting has effects on innovation and the absorptive capacity of new ventures, as both are effected by firms knowledge base (Cohen and Levinthal 1989). In other words, an explorative opportunity development phase gave companies knowledge and experience, not just of the product but also of the development practices, which they exploited in later product development projects. The second way the growing formality of processes manifested was as an increased focus on the front-end activities and added evaluation gates to avoid wasted development efforts. This was motivated by reassessment of development activities due to a negative experience, often from either finishing product development and realizing the product should not be launched or having already launched a product and pulling it out when it did not meet market expectations. Baumard and Starbuck (2005) suggest the smaller the company, the more likely it is to learn from product failure. The corrective actions manifested as added emphasis on concept development, the companies wanted to make sure the product under investigation would be in line with their portfolio and brand strategy or image. Moreover, some companies had introduced stricter decision points for concept assessment before moving to detailed development and later project assessment just prior to launch.

Van den Bosch et al. (1999) suggest that companies in stable knowledge environments focus on exploitative activities because their existing knowledge base already corresponds closely to what is needed to operate. This was also evident in the present study, as for example companies in the flavorvariant category showed overall less explorative efforts than those in the new-to-self category. Even though the case companies seemed to identify opportunities for new products and product variation exploratively, many trusted their own judgement from that point onward. This meant building the 
product concept and business case around the initial idea with very little search for outside input and conducting concept assessment with only internal validation or proceeding to detailed development even without any formal evaluation. Many case companies, and notably all cases in the flavor-variant development category, indicated this by stating that they primarily use and trust their own sense of taste. In general, the three identified process types suggest that small companies use explorative and exploitative experimentation at different phases diversely depending on the enacted product development process type, which in turn is tied to the company's previous experience in the type of product.

Beyond using both explorative and exploitative experimentation within certain stages of their process, companies changed their overall approach when switching the development goal for a product. This suggests a link between a development goal and the specific process which helps to achieve it. For example, if a company developing primarily flavor variant products pursued a significantly new product in which they had no experience with, their activities shifted towards more explorative actions typical for the new-to-self development cases. This includes alertness in opportunities beyond just flavors as well as increased concept development activities, more explorative testing, and exploring unfamiliar areas in detailed product and production process development.

The dynamic environment of the food and beverage sector reflected to rapid flavor creation and constantly being on the lookout for new possible ingredients, as well as keeping in mind wider trends such as the concern for the natural environment and health issues. Experiments were constant features in all phases and companies, however, most of these were conducted internally. As a design practice, prototyping and experimentation is considered central to innovation, especially with increasing emphasis on problem solving to address customer needs and creating opportunities (Brown, 2008). This explorative experimentation is highlighted as a core component in customer-oriented design thinking (e.g. Liedtka, 2014; Carlgren, 2016). However, the internal tests conducted by case companies were more reminiscent of validative prototyping often described in engineering design (Ulrich \& Eppinger, 2012), from which food development practitioners also draw from (Earle et al., 2001). The threshold for internal experimentation was low and ranged from one-person testing of multiple alternatives (such as creating alternative flavors), to other founders providing feedback to the main experimenter around the product or issue, to a joint effort of the entire team working collectively. External-facing experiments and co-creation were usually conducted in later stages of the process and as more separate instances. The focus tended to be around validation, rather than creating new directions or ideas to explore. However, findings from validative experiments could serve as groundwork for later revisions of potential new directions, as was seen in the cases of new food category products. Perhaps surprisingly, the type of experiments used seemed less connected to the product category and overall development goals than what the overall development process was. Similar experiments were seen in premium food and beverage ventures, as well as new food products. Although the current study is based on the cases of eight Finnish food and beverage ventures, and cannot thus be generalized to other organizations, industries or ecosystems, the results suggest that internal experiments seemed to be a characteristic way of learning for these companies. Indeed, Miner and colleagues (2001) suggest that learning from experiments is retained longer than those gained in more improvised or trial-and-error exploration. However, unlike their characterization of experimentation as deliberate and systematic use of varied conditions, the experimentation activities of the new ventures were characterized more as intentional exploration activities than a broad variety of variations at a single point of time. Internal experiments were more or less constant, but less frequent external-facing experiments were used to both gather feedback and validate development decisions and to help create a market for new types of products. More research is needed to explore the effectiveness of different types of experiments in different phases of the development process, as the results suggest more nuances are needed for examining different types of experimentation practices rather than focusing only on whether or not experimentation is present in the development process. The results of the current study highlight the rapid approach that small ventures take to new product development and how their processes and practices are shaped by introducing varying types of experimentation.

\section{REFERENCES}

Acs, Z.J., Autio, E. and Szerb, L. (2013), "National systems of entrepreneurship: measurement issues and policy implications", GMU School of Public Policy Research Paper No. 2012-08.

Audretsch, D.B. (2002), "The dynamic role of small firms: evidence from the US", Small Business Economics, Vol. 18 No. 1/3, pp. 13-40. https://doi.org/10.1023/A:101510522 
Audretsch, D.B., Bönte, W. and Keilbach, M. (2008), "Entrepreneurship capital and its impact on knowledge diffusion and economic performance", Journal of Business Venturing, Vol. 23 No. 6, pp. 687-698.

Baker, T. and Nelson, R.E. (2005), "Creating something from nothing: resource construction through entrepreneurial bricolage”, Administrative Science Quarterly, Vol. 50 No. 3, pp. 329-366.

Braun, V., and Clarke, V. (2006), "Using thematic analysis in psychology”, Qualitative Research in Psychology, Vol. 3 No. 2, pp. 77-101. http://dx.doi.org/10.1191/1478088706qp063oa

Brown, T. (2008), “Design Thinking. Harvard Business Review”, (June), pp. 84-92.

Carlgren, L., Rauth, I., and Elmqvist, M. (2016), "Framing design thinking: The concept in idea and enactment", Creativity and Innovation Management, Vol. 25 No. 1, pp. 38-57.

Chell, E. (2004), "Critical incident technique”, in, Cassell, C. and Symon, G. (eds.) Essential Guide to Qualitative Methods in Organisation Studies. SAGE, London, UK, pp. 45-60.

Cooper, R.G. (1983), “The new product process: an empirically-based classification scheme”, $R \& D$ Management, Vol. 13 No. 1, pp. 1-13. https://doi.org/10.1111/j.1467-9310.1983.tb01124.x

Cooper, R.G., and Kleinschmidt, E.J. (1988), "Resource allocation in the new product process", Industrial Marketing Management, Vol. 17 No. 3, pp. 249-262. https://doi.org/10.1016/0019- 8501(88)90008-9

Cooper, R.G. (1994), “Third-Generation New Product Processes”, Journal of Product Innovation Management, Vol. 11, pp. 3-14. https://doi.org/10.1111/1540-5885.1110003

Earle, M., Earle, R., and Anderson, A. (2001), "Food Product Development", Woodhead Publishing Limited, England. ISBN: 1855734680

Eisenhardt K.M., and Graebner M. (2007), "Theory building from cases: opportunities and challenges", Academy of Management Review, Vol. 50 No. 1, pp. 25-32. https://doi.org/10.5465/amj.2007.24160888

Fisher, G. (2012), "Effectuation, causation, and bricolage: a behavioral comparison of emerging theories in entrepreneurship research", Entrepreneurship Theory and Practice, Vol. 36 No. 5, pp. 1019-1051.

Flanagan, J.C. (1954), "The critical incident technique”, Psychological Bulletin, Vol. 15, pp. 327-358.

Grunert, K.G., and van Trijp, H.C.M. (2014), “Consumer-Oriented new product development”, In Encyclopedia of Agriculture and Food Systems (pp. 375-386). Elsevier.

Hörte, S-Å., Barth, H., Chibba, A., Florén, H., Frishammar, J., Halila, F., Rundquist, J. and Tell, J. (2008), "Product development in SMEs: a literature review", International Journal of Technology Intelligence and Planning, Vol. 4, No. 3, pp. 299-325. https://www.doi.org/10.1504/IJTIP.2008.020099

Liedtka, J. (2014), "Perspective: Linking design thinking with innovation outcomes through cognitive bias reduction”, Journal of Product Innovation Management, Vol. 32 No. 6, pp. 925-938.

Linnemann, A.R., Benner, M., Verkerk, R. and van Boekel, A.J.S. (2006), "Consumer-driven food product development”, Trends in Food Science \& Technology, Vol. 17 No. 4, pp. 184-190.

March, J.G. (1991), "Exploration and exploitation in organizational learning", Organ. Sci. Vol. 2 No. 1, pp. $71-87$.

Miner, A.S., Bassoff, P., Moorman, C. (2001), "Organizational Improvisation and Learning: A field study", Administrative Science Quarterly, Vol. 46, pp. 304-337. https://doi.org/10.2307/2667089

Phene, A., Tallman, S. and Almeida, P. (2012), "When do acquisitions facilitate technological exploration and exploitation?", Journal of Management, Vol. 38 No. 3, pp. 753-783.

Ries, E. (2011), “The lean startup: How today's entrepreneurs use continuous innovation to create radically successful businesses", Crown Business, New York. p.336.

Rekonen, S. and Hassi, L. (2018, "Impediments for experimentation in novice design teams", International Journal of Design Creativity and Innovation. Vol. 6, No. 3-4, pp. 235-255.

Shepherd, D.A. (2015), "Party On! A call for entrepreneurship research that is more interactive, activity based, cognitively hot, compassionate, and prosocial”, Journal of Business Venturing, Vol. 30 No. 4, pp. 489-507.

Suwannaporn, P. and Speece, M. (2010), "Assessing new product development success factors in the Thai food industry”, British Food Journal, Vol. 112 No. 4, pp. 364-386.

Ulrich, K. and Eppinger, S. (2012), "Product design and development", 5th edition. McGraw-Hill, New York, NY. p. 402. ISBN 978-007-108695-0

Uotila, J. Maula, M., Keil, T. and Zahra, S.A. (2009), "Exploration, exploitation, and financial performance: analysis of s \& p 500 corporations", Strategic Management Journal, Vol. 30, No. 2, pp. 221-231.

Van den Bosch, F., Volberda, H., de Boer, M. (1999), "Coevolution of firm absorptive capacity and knowledge environment: organizational forms and combinative capabilities”, Organization Science, Vol. 10 No. 5, pp. 551-568.

\section{ACKNOWLEDMENTS}

This research has been funded partly by the Jenny and Antti Wihuri Foundation. We are thankful for this funding, the support of the larger Aalto Design Factory research team, as well the time of the interviewees from the case companies. 